Félix Armando Núñez

\title{
Homenaje a don Enrique Molina
}

\begin{abstract}
"Feliz aquél que calla o niega por amor a la palabra justa, si algún día encuentra que para lograrla, como yo ahora, debe recurrir a las cálidas voces del olvidado regocijo y la perdida admiración.-Pedro Prado.
\end{abstract}

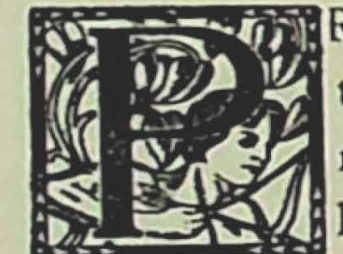

RIMERO, señores, fue como una indecisión entre el estupor de la tragedia antigua y la elegía pura que sonríe con la mirada infantil que se ha bañado en una lágrima donde ya no queda el sentimiento que la motiva como en un cuadro de Greuze, el ingenuo pintor de ingenuas doncellas que sonríen alegremente a la vida después de haber llorado; la oscilación entre el ditirambo que exalta las pasiones y el suave acorde de la lira que las reprime; primero, el frío de las cimas, el aletazo del aire helado en las cumbres solitarias donde apenas si se respira en la ininterrumpida quietud de la majestad; luego el impe-

(1) Este discurso fue pronunciado en la velada organizada por los amigos y compañeros de los cursos de humanidades del Liceo de Concepción, con motivo del alejamiento de don Enrique Molina de la enseñanza fiscal, después de cuarenta años de fecunda labor pedagógica. 
rativo de armonía que en la dulzura de los valles hace a la vida posible; primero el temor de emprender una obra superior a mis fuerzas y en seguida la obligación de hablar ahora como un toque de clarín surgido de lo más profundo de la conciencia en un acorde demoníaco al que se responde con toda la fuerza de los pulmones: "A sus órdenes, mi capitán".

Perplejo estaba, alegre, triste: era la helada confusión del que experimenta sucederse en el vértigo de un momento las más variadas emociones. Ahora ya sé: ni el miedo a la retórica, ni la retórica misma podrían detenerme. He venido a pagar un tributo conmovido de justicia y gratitud a la noble tierra de Chile en una de las más faustas solemnidades que en los anales de su cultura ejemplar en la América española recordarán los hijos de este país, y no importa que se diga alguna vez que esta límpida fecha queda grabada en un bronce romano con fuego de los trópicos, si a decir no se opusieran todavía la quemante sinceridad de mis palabras y el amor al tono heroico, grato a una tierra pétrea y suave, donde sobre la lava de los volcanes como la del Osorno, que hollamos como algo sacro, crece la gracia del ulmo aborigen que reviste en el mayor alarde, de floral delicadeza una gala de llovidas estrellas matutinas y donde se escucha la canción eterna del agua que se tornasola entre los bosques y las rocas en el mediodía de más clásica perfección en que nuestras pupilas se han maravillado jamás.

Perdonadme, señores, si como vuestro poeta pueda jactarme yo de decir que en esta ocasión magnífica, después de haber negado mucho tiempo, por amor a la palabra justa, recurra hoy a las cálidas voces del olvidado regocijo y la perdida admiración, para hacer el elogio de don Enrique Molina, quien, por su importancia en la cultura del continente, impone la actitud de descorrer el velo que cubre el mármol, o mejor el bronce otra vez, o el simple simulacro erigido en vida a uno de esos hombres egregios de quienes una patria espera aún lo mejor de su energía, a pesar de lo mucho que dieron... Inmolarse todo en su obra es el espectáculo más sublime que el mundo moral pueda ofrecer. Hegel, mencionado por uno de los más precla- 
ros varones de la España actual: "En la historia todo lo ha hecho la pasión; pero entiéndase bien, corrige el citado filósofo, la pasión fría". Es decir, y valga mi exégesis, la fuerza unida a la tranquilidad, que es capaz de dominar con señorío de delicadeza, porque es capaz de dominarse a sí misma.

Este señorío que se siente apenas, señorío de maneras, señorío de pulso firme y de criterio saludable es lo primero que impresiona en la figura de don Enrique Molina, en quien el equilibrio intelectual se rompe a veces en corregidas actitudes de Alonso Quijano, "El Bueno", corregidas actitudes que según Américo Castro, cuya opinión compartimos del todo, es la quintaesenciadamente cervantesco, por oposición a lo quijotesco que no es cervantesco, porque Cervantes es la salud estética misma, el orden, la manera.

"No es la oportunidad de decir quién es don Enrique Molina -expresa en columnas de honor "El Mercurio" de Santiago, en su editorial del $10^{\circ}$ de este mes, con austera belleza de comentador avezado-, don Enrique Molina, maestro de la juventud, pensador y literato con honda raigambre en los círculos intelectuales del país y del extranjero, creador de una Universidad, hija de su empuje y de su fe en el porvenir de la enseñanza". Para mí, queridos compañeros del liceo, sí es la oportunidad: de agradecimiento profundo que a mi vez os agradezco con todas las fuerzas de mi alma, ya que en vuestro nombre hablo por especial manera. $Y$ es tan oportuno el momento, que en la intensidad de mi emoción, sintiéndome hondamente feliz de expresarlo se me vienen a la mente los conocidos versos de Goethe en el "Fausto": "Pueda yo decir al momento fugaz, detente que así eres bello".

Cuando los que nada han hecho censuran, debería ser obligado el silencio en torno a su crítica si ésta recae sobre hombres-montañas, ante quienes los mismos enemigos - si es que los tienen- se descubren casi inconscientemente por respeto. Napoleón, en el Belerefonte, ultrajado por una oficialidad menos que mediocre que lo custodia, llega al puerto de Plymouth. El prisionero se asoma tranquilo al puente. La multitud se descubre ante el enemigo en desgra- 
cia, en un silencio que la historia ha recogido para la eternidad. Todos los valores se discuten y hay argumentaciones para probarlo todo; pero en el fondo, aunque luchen contra sus propias vanidades y digan lo contrario de lo que piensan, los hombres reconocen al Hombre.

Frecuente es, y en demasía, por ligereza de juicio o torcida intención, parangonar a los que han actuado lustros y lustros en primera fila con los que, episódicamente, han tenido una pulcra figuración momentánea, cuyo prolongarse en la sinuosa curva de los acontecimientos históricos o sociales no pasa de ser una conjetura substraída acaso de la realidad por un buen hado. Pero ante cuarenta años de actuar prócer no queda sino inclinarse con un gesto de rendida admiración. Estos cuarenta y tres años de la vida pública de don Enrique Molina, representan una vida ejemplar, en cuyo proceso se acusan, con acentuados lineamientos, caracteres de diversas edades que no en vano la biología y la psicología han tratado de definir; mas, en el que queda siempre como en el maestro de Weimar, maestro también del maestro, un rasgo permanente de adolescencia que se traduce en una incesante capacidad de renovación, que aprovecha con sabiduría la experiencia de los años, para mezclar al conocimiento profundo de los hombres y de las cosas un destello de idealidad pareja de la grata sophrosine platónica o del buen natural en que confluyen en un logro de vida superior, hecho segunda naturaleza animadora, la ética y la estética de las relaciones sociales, la simpatía, que comprende siempre y la razón que contiene el impulso ardiente de generosa capa para evitar el inútil martirio.

En los albores es el estudiante y el profesional, adolescente aún, que en Chillán y en Talca arremete con gallardías de andante caballero, las cuales, atemperadas con el curso de los años no le abandonarán del todo ya más; después la meditación sistemática, las disciplinas filosóficas, la estimación del conjunto armonioso antes del arranque valiente, que pudo ser temerario sin esta contención intelectual, en que hay algo de Leonardo y mucho de la frecuentación de Dickens y de Goethe; todo ello con el actual resultado: la perso- 
nalidad saludable como el aire de las alturas, la mano vigorosa en el timón, la cual inspira confianza para trabajar sin sobresaltos en esta larga o breve travesía que es nuestra vida.

Pero debo volver sobre la formación de esta personalidad de que una suerte venturosa-nos ha hecho insigne regalo.

Cumplido un siglo de la Revolución Francesa, el Presidente Balmaceda fundaba en la muy noble Santiago de Chile el Instituto Pedagógico, plantel en que había de formarse el profesorado de educación secundaria y establecimiento único en su género en la América española, donde se han graduado maestros de muchos países hermanos $y$, por consecuencia, hogar ilustre de fraternidad hispanoamericana y lumbre que ha contribuido a dilatar el renombre de esta tierra más allá de sus fronteras. Un nuevo tipo de liceo iba a nacer de sus aulas. Recuerdo que el notable filólogo, doctor Rodolfo Lenz, nos decía de regreso de un viaje de estudio a Europa, efectuado después de la guerra europea, que los liceos chilenos nada tenían que envidiar a los más adelantados países del mundo. Tal declaración debe enorgullecernos todavía.

Sea como fuere, el Pedagógico, a cuyo primer curso perteneció don Enrique Molina, significó también una revolución en la enseñanza secundaria. Determinar la magnitud de sus proyecciones corresponde al historiador, vale decir, a la perspectiva que permite apreciar en su justo relieve a los hombres y los acontecimientos. ¿En qué proporción los sucesos y las personalidades recias se mezclan en la evolución de una cultura? Carlyle, Emerson, Nietzsche, entre otros, se inclinarán en favor de los grandes hombres. Tesis exagerada, tal vez, pero que es la única que satisface a los de su estirpe. No puede el hombre superior aceptar lisa y llanamente que él sea hijo de las circunstancias. El siente que crea o modifica circunstancias y nosotros también así lo aceptamos, sin menoscabo de un determinismo riguroso. El verdadero maestro en nuestro concepto debe alentar las individualidades poderosas que encuentra en la asamblea de alumnos cuyas almas interpreta. El alumno inteligente podrá volverse consciente de su valer, pero no vanidoso. El éxito de don Enrique 
Molina como educador no radica principalmente en haber sido exigente con sus alumnos, que acaso no lo fue nunca, sino en ésta actitud natural para exaltar la personalidad humana, en esa unción varonil que su palabra ha tenido siempre para hacernos creer que algo valemos, que el porvenir es en nosotros como una tierra de promisión. Ningún educador ha poeído acaso en Chile esa aptitud singular. Educador de alumnos y de educadores, su momento más cabal está en el corazón de las generaciones. Ningún complejo de inferióridad, herida más honda que todas las heridas, porque es herida en el alma, ha cundido por obra suya. Y qué grande nos lo imaginamos en sus combates en Talca, donde él mismo representaba, sin pedantes doctrinas de detalle, las nuevas escuelas antes de Dewey, por una sorprendente intuición, o por sus lecturas de Goethe o los antiintelectualistas como William James.

El valer de don Enrique Molina no es el de los que andan por ahí acuñados en falsa moneda o afincados en la destreza fácil del panegirista de ocasión. Es un valor intelectual y moral que ya nadie podrá disputarle. Inconmovible como la roca del Huelén en el estupendo valle del Mapocho, asiste como actor y protagonista a un proceso de importancia capital en la cultura de Chile y América. Mientras Augusto Thompson, cuyo influjo continúa en Pedro Prado, Mariano Latorre, Baldomero Lillo, Fernando Santiván, Rafael Maluenda, Gabriela Mistral y otros escritores de vasta significación en las letras chilenas, se entregan apasionadamente a la lectura y al comentario de los grandes novelistas, cuentistas y poetas extranjeros - llámense éstos Tolstoi, Zola, Ibsen, Nietzsche, d'Annuzzio-, don Enrique Molina, sin dejar por ello de informarse continuamente de la producción literaria de extraños y propios, abraza con el amor del marinero que sólo en las faenas del mar encuentra adecuada complacencia, la labor de reflexión profunda que significa la filosofía, y le son familiares William James, Lester Ward, Guyau, Bergson, sobre los que ha escrito libros que constituyen en las primeras décadas del siglo XX la pieza de resistencia de ese al parecer festín intelec- 
tual, pero en verdad torneo de vigor supremo, en que se han dado cita los más esclarecidos espíritus de esta generación. Escribe sin rebuscamientos ni escuela - guiado sólo por una facilidad ínsita a su carácter- Facilidad para pensar, facilidad de organizador y de improvisador, a la vez que da el tono en las asambleas intelectuales a que ha concurrido, facilidad para dejar en paz a los espíritus agriados, no se sabe si la armonía que emana de su continente es don natural o la obra maestra de un alma incesantemente consagrada a su perfeccionamiento. De todos modos sus actividades de cualquier naturaleza que sean - pedagógicas, sociales, intelectuales - tienen la calidad de las aguas que han descendido de las cordilleras, porque mientras otros frecuentaban el trato de personas livianas, su verdadero e fintimo ambiente lo ha constituido la conversación reposada y constante con los más grandes poetas y pensadores de todos los tiempos. No han sido ajenos para él los sinsabores y amarguras de la lucha por la vida. Pero maestro por derecho divino, en horas que en otros pudieron ser de tribulación o derrota, nos ha dicho simplemente: "la actitud filosófica". El valor, la templanza, la justicia y la prudencia: ninguna de estas virtudes lo es por sí sola si no va a acompañada de las otras, pensaban los estoicos. La etopeya de don Enrique Molina queda circunscrita con esta sublime moral como una piedra de nítidas aristas.

La trascendencia de esta figura que está muy lejos de fallar en la fila de los mejores - junto a los Sarmiento, los Bello, los Lastarria, los Vicuña Mackenna, los Amunátegui- se nos representó gráficamente un día que viajábamos allí donde se confunden la Suiza chilena y la Suiza argentina, en el camino a Bariloche. Nombres chilenos representaban el empuje civilizador de la raza. Puerto Montt, Puerto Blest, el boquete Pérez Rosales. De pronto, en la mayor eminencia del trayecto, la lengua Frías ya en territorio argentino, pero bautizada con un nombre chileno. Allí ese inmenso vaso de agua con el augusto silencio de las alturas y la gracia de una espesa vegetación que trepa hasta encimar las riberas cortadas a pico, y sirvien- 
do como de guía infalible en la pureza metálica del cielo la mole magnífica del volcán Tronador con sus nieves eternas, del que parece irreverencia apartar la vista para detenerla en los detalles del paraje.

\section{DISCURSO DE AGRADECIMIENTO DE DON ENRIQUE MOLINA}

He sido objeto en estos días con motivo de mi retiro de la enseñanza del Estado de manifestaciones tan brillantes y afectuosas que me han emocionado con una intensidad que no había experimentado en mi vida.

He pasado horas de simpático y expansivo compañerismo invitado por los profesores de la Escuela Anexa y empleados administrativos del liceo, manifestación que me fue ofrecida en términos conmovedores por $\mathrm{mi}$ inteligente colaborador en la secretaría del establecimiento y leal amigo profesor don Sirinio Saavedra.

He asistido a un amenísimo acto teatral organizado también por los profesores de la Escuela Anexa con el concurso de sus pequeños alumnos que se desempeñaron como bien preparados artistas y contando además con la cooperación de encantadoras niñitas del Liceo Carmela R. de Espinoza.

El Club Rotario me honró dedicándome su sesión semanal del sábado último, ofrecida en los más benévolos términos por mi distinguido ex discípulo y amigo, su presidente don Manuel Maldonado.

Tanto la prensa de la capital como la de esta ciudad, ha emitido en estas circunstancias juicios tan favorables que constituyen para mí un galardón superior a cuanto podía esperar.

Ahora esta magnífica y solemne velada, que han organizado mis amigos y compañeros de los cursos de humanidades del liceo. $Y$ en esta ocasión ser objeto de la palabra elocuente, impecable en la forma, ardiente y maciza en el fondo, de mi gran amigo, el inspirado y hábil poeta y profesor don Félix. Armando Núñez, palabras que han sido el ropaje de conceptos elogiosos, de los cuales bien pudiera ser digno si se miran los afectos que mi pecho abriga, pero no por 
los méritos que esos conceptos suponen. Escuchar aún la palabra emocionada y sentida del aventajado alumno don Jorge Moore. Todavía, me habéis hecho hoy mismo el obsequio de una bella obra, presentada con el mensaje de una oración de forma exquisita pronunciada por mi amigo el culto y talentoso profesor don Carlos Martínez Toledo. Al agradecérosla particularmente os dije que ese hermoso busto de mujer me acompañaría siempre al lado de mis libros y que en su dulce silencio, invitador al estudio, me hablaría sin cesar de vosotros.

De sobra comprenderéis que todo esto significa la saturación del alma con sentimientos de la más optimista placidez.

Pero no vayáis a creer que la enumeración que acabo de apuntar obedece al más leve motivo de vanidad. ¡Ah, no! En cada momento me he venido preguntando: ¿Qué he hecho yo para merecer estas cariñosas muestras de adhesión? ¿De qué suerte agradecerlas debidamente? $\mathrm{Y}$ como una necesidad imperiosa de mi emoción tengo que repetirles a algunos y expresarles a otros por primera vez cuán honda es, cuán duradera será mi gratitud.

De ordinario el pasado de la propia vida se encoge como una línea insignificante para dejar todo el espacio de la conciencia a la expansión de las preocupaciones del presente.

Las palabras y actos de que he sido objeto han obrado en estos días como espejos de aumento al efecto de cuyo calor y luz mi pasado se ha desentumecido $y$ ha cobrado volumen ante mis ojos. Ha sido como un testigo que he llamado a declarar en este juicio que yo mismo me he abierto para ver si soy acreedor a lo que estoy recibiendo.

Vosotros sabéis que el Instituto Pedagógico fue fundado para formar profesores de enseñanza secundaria. Los alumnos del primer curso de dicho Instituto salimos a fines de 1892, para llevar a cabo una reforma trascendental en esa rama de la enseñanza pública. Nos llamaron entonces los concéntricos por el nombre y peculiaridades del plan de estudio que se iba a implantar y que en sus líneas básicas ha continuado hasta ahora. 
Los liceos se encontraban, por lo general, en un estado deplorable. Los profesores eran todos aficionados. Para profesor de castellano, historia o filosofía, se buscaba a un abogado; para que enseñara ciencias naturales a un médico; como maestros de lenguas vivas a extranjeros de la respectiva nacionalidad. Rectores eran personajes de influyente situación social o política, sin especial preparación pedagógica. Sin embargo, solía darse el caso en una y otra categoría de rectores y profesores sobresalientes por su competencia y dedicación.

También la difusión por el país de profesores titulares contribuyó a que muchos que tenían condiciones ingénitas de educadores, llegaran sin seguir los cursos del Pedagógico a ser maestros distinguidísimos.

El ambiente moral de los liceos, como asimismo sus edificios, instalaciones y material de enseñanza dejaban también bastante que desear. La opinión pública estaba menos preparada, se interesaba menos por las cuestiones educacionales y no era tan exigente en sus juicios como en nuestros días. Entonces se mantenían incólumes, a pesar de sus graves defectos, liceos que hoy habrían sido barridos por la condenación general.

Aquel momento fue una encrucijada decisiva en mi vida. $\mathrm{Re}$ solví consagrarme por completo al magisterio y al estudio y no a la abogacía, cuyos cursos estaba por terminar. Pensé que nuestro país necesitaba más profesores que abogados y no quería ser profesor a medias: Quien sabe si mi resolución no fue otra cosa que la obra de un instinto salvador que, dada mi falta de aptitudes, me libró de ser un mal abogado.

Pero no quería ser dómine.

No me tentaba la técnica de la enseñanza y de algunos defectos que de esto se derivan, no me he corregido nunca. Me atraía la comunicación de las almas, el fuego que en ellas se enciende, tanto en el maestro como en los discípulos, las simpatías mutuas que se despiertan al calor de la obra educativa.

Siempre me acerqué a mis discípulos con espíritu de compren- 
sión y cariño. Me explicaba y perdonaba interiormente sus faltas, corrigiéndolas sólo para que de su carácter no estuviese ausente la disciplina, sin la cual ningún hombre puede llevar una vida digna ni servir a la sociedad. Los consideraba fuerzas en potencia que había que cultivar. Innumerables han sido las veces que he tenido yo más confianza en su porvenir que ellos mismos, y he despertado las energías del Lázaro que dormía en sus almas. Pero qué tarea tan bien recompensada es ésta, tanto en el momento que se toca el resorte eficaz de voluntades adolescentes por el placer íntimo que ello procura, como más tarde con la flor espontánea del reconocimiento de los jóvenes.

Hace más de treinta años sintetizaba lo que había venido poniendo en práctica en las siguientes palabras:

"Es indudable que para que la tarea de un profesor sea provechosa, influyen más que una serie de máximas sobre procedimientos técnicos el concepto general de la vida que él tenga, una elevada idea de su misión y un sentimiento profundo de lo que le corresponde hacer en la sociedad".

Digamos: darle a la vida un alto y vigoroso sentido moral. C6mo se prestan las clases de historia y filosofía para esta labor de afirmar valores y de sugerir ideales. La clase, sin la obsesión del programa exorbitante que urge embutir en la cabeza de los alumnos y sin hacer de ella una caza de muchachos que ignoran sus tareas, es una hora de deliciosa y fecunda expansión espiritual.

Aunque no se pretenda llegar a las cumbres del heroísmo ni de la santidad, entona el alma compenetrarse con los héroes, santos y grandes hombres que han tenido el carácter de dar a su vida un sentido de actividad creadora, de abnegación, en favor de una idea, de la patria o de la humanidad.

Las leyendas heroicas de la Grecia nos brindan su lección de valor consagrado al servicio social.

Es saludable convivir el sacrificio de Sócrates por defender su libertad de juzgar y mantener la consecuencia en sus doctrinas.

Siempre es grato repetir las palabras aladas de Jesús. 
Los estoicos nos enseñan a conservar la serenidad del ánimo y el indispensable dominio de sí mismos.

Hacemos con los puritanos ingleses el esforzado viaje de la "Mayflower" a la América del Norte para asegurar la libertad de conciencia.

Llegamos transidos de admiración a las orillas del Delaware con los cuáqueros de Guillermo Penn, que practican en verdad el evangelio de la fraternidad humana y para colonizar no disparan un tiro, sino que les compran a los indios los terrenos que necesitan y los indios dicen: "Seremos eternamente amigos de estos hombres hermanos que no ejercitan la violencia".

El espiritu de empresa, de resistencia y de sacrificio de los conquistadores españoles es como una semilla arrojada en la tierra del Nuevo Mundo que rebrota poderosa en los héroes creadores de la independencia americana.

Es glorioso morir como Lincoln por haber abolido la esclavitud.

Y cuánto héroe, cuánto sabio y artista, cuánto inventor más. Desde el Cid a Cervantes, desde Juana de Arco a Zola, desde Gutenberg a Goethe, desde Miguel Angel a Marconi, desde Bolívar, San Martín, O’Higgins, a Bello y Montalvo, la galería es inagotable.

Sin desdeñar el suministro de informaciones y datos, ni el razonar científico y filośffico, la modesta sala de clase se convierte en un lugar donde se celebran liturgias humanas y donde se da consistencia al carácter alrededor de las ideas céntricas de deberes que cumplir y responsabilidades que asumir. Sobre todo -así queda de manifiesto con las reflexiones del aula - en las circunstancias difíciles, en los momentos de prueba, no hay otra brújula más segura para la voluntad que considerar claramente las responsabilidades que nos incumben.

El liceo es también un centro de armonía social y de tolerancia. No se menosprecia al muchacho pobre o de condición humilde; tampoco goza de privilegio alguno el hijo de vecino opulento. Aquél recibe la ayuda y cooperación que éste no ha menester. No se hace de la fortuna legítimamente adquirida un motivo de vituperio. No 
busca pues su orientación el liceo ni en un falso aristocratismo ni en un descarriado bolcheviquismo. Mide a sus alumnos con el cartabón de los valores intelectuales, morales y cívicos y los acostumbra a usar igualmente de esta medida para juzgar a los demás.

En el liceo no se atacan las creencias religiosas y los colegios particulares son, por lo general, objeto de la mayor ecuanimidad de parte de las comisiones examinadoras que van a fiscalizarlos.

Los progresos de la enseñanza secundaria en el último medio siglo han sido bastante apreciables en la preparación del personal docente y administrativo, en los planes de estudio, en el programa y en la persecución del desarrollo integral de las facultades del educando. Algo se ha hecho también para mejorar los edificios, las instalaciones y el material de enseñanza.

Habría mucho que decir de reparos a menudo exagerados que se hacen a esta rama de la educación sobre el enciclopedismo que desperdiga los espíritus e impide su fecunda concentración, sobre que no prepara a los jóvenes para ganarse su existencia y los encamina sólo a las profesiones liberales y a la empleomanía; pero no me corresponde en esta ocasión discurrir sobre tales problemas. He querido detenerme únicamente en puntos que el educador no puede descuidar cualquiera que sea la orientación que se dé a la enseñanza, puntos que tienen que ser la espina dorsal de toda vida, como son los que se refieren a la disciplina moral.

Me imagino un diálogo con mis discípulos al respecto:

-Y usted que viene de una lejanía de tantos años, ¿qué nos dice de lo que debe ser como una destilación dejada por el tiempo en su espíritu? -me preguntarían.

- Hay ciertos conceptos señeros que esencialmente no cambian. Los progresos técnicos parecen transformar por completo la faz del mundo, pero para el alma son más que una especie de superestructura, como los son las propias manifestaciones materiales de esos progresos sobre la constitución de un nuevo planeta. Un hombre de hogano va de Santiago a Buenos Aires en avión en cuatro horas en lugar de los dos, cuatro u ocho días que empleara el hombre de 
antaño en hacer idéntico viaje en tren o a lomo de mula. Aquel atiende sus asuntos en automóvil y no a caballo o a pie. Despacha su correspondencia en máquina de escribir y no con pluma de ave o de acero. Oye las vibraciones de la radio de todo el mundo y va al cine. Pero el hombre de hogaño tiene el deber de trabajar como el de antaño y más aún para poder aprovechar los adelantos que la técnica le ofrece. Tiene la obligación de usar su auto para el bien y no para dar golpes de mano o raptar una muchacha. Tiene la obligación de emplear su máquina de escribir para decir la verdad y no para mentir o mandar anónimos. O sea, bajo los cambios exteriores siguen corriendo para la nutrición del alma las mismas claras fuentes seculares que hablan del trabajo, de la veracidad, de la honradez y de la condenación de la mentira.

-Entonces si los principios morales son tan antiguos y claros, ¿por qué hay problemas?

-Los principios son antiguos, pero la tentación es siempre nueva ya se presente o no bajo el reclamo de inventos recientes. A su hora cada mujer es una Eva y cada hombre un Adán, con la diferencia respecto de la leyenda paradisíaca de que el diálogo suele empezarlo él y no ella. El amor, viejo como la vida, es una sinfonía enteramente nueva, cuyas resonancias llenan el ser que lo siente de verdad. La ley del trabajo es tan antigua como la sociedad humana y la pereza nos acecha todos los días, tomando las más variadas formas, empleando los más sutiles sofismas, para tentarnos. La condenación del robo es tan añeja como el Decálogo y la tentación de apoderarse de lo ajeno, con su secuela de mentiras y de toda clase de perturbaciones es irresistible para algunos. De la moderación y templanza en los goces sensuales hablan las más remotas filosofías y muchos hombres no son más que una piltrafa a causa de sus excesos. Es cierto que un escritor ha dicho que la tentación se ha hecho para caer en ella; pero ésta no es más que una ingeniosidad literaria. Hay cosas que están en su lugar en la literatura y en el cine, pero jay! del que, creyéndolas imagen de la vida y olvidándose 
de los principios que esas cosas suelen atropellar en la novela y en la pantalla, trata de aplicarlas a su realidad porque las consecuencias serán desastrosas. El hombre no puede substraerse a lo que aconsejan la disciplina y el dominio de sí mismo sin correr el riesgo de deshacer su integridad espiritual, de caer en los vicios que disuelven el carácter, de ser como el sobreviviente de su propio cadáver.

El rectorado tiene los relieves de una escuela de lealtad y de valor. De lealtad para con todos, para los jefes y los subalternos, para los de arriba y los de abajo. De valor en un sentido negativo para despreciar y no responder a ningún ataque injustificado o calumnioso; en un sentido positivo, para ser siempre justo y vivir en la verdad. Por supuesto que los rectores no van a pedir el privilegio de estas virtudes que deben ser patrimonio de todos los hombres. Pero es menester además que en las relaciones de jefes y compañeros no falte nunca un blando latido cordial. Así lo he deseado siempre. Rectitud penetrada de afectos o afectos con base de rectitud; estas fórmulas que me parecen admirables para la vida podrían expresar cuál ha sido mi inspiración.

No pretendo de ninguna manera señalar normas con lo que he dicho. Mi distinguido sucesor en el liceo me superará fácilmente en lo poco que he llevado a cabo. Los profesores que me reemplacen me superarán también si es que no me han superado ya con las muestras que hayan dado de sus capacidades docentes. Los discípulos deberán superar a los maestros. Esta es una forma del progreso que tenemos que acatar y cuya realización debemos desear en bien del mejoramiento de la colectividad.

No he considerado jamás una manifestación que se me haya hecho como el pago de una deuda anterior, sino como un crédito que se me abriera sobre futuras actividades mías. Cuánto más en este caso dada la grandeza y espontaneidad de los actos que me habéis generosamente ofrecido, queridos amigos del profesorado y jóvenes estudiantes. Aquí me tenéis, pues, con el alma encendida de gratitud. Soy como un viajero que ha llegado al término de la mayor jornada de su vida y ahí se encuentra rodeado de almas amigas que le de-. 
paran instantes de la más perfecta felicidad que es posible alcanzar en la Tierra. Con la esencia de vuestros afectos ha cobrado nuevo brillo la lámpara del viajero alumbradora del camino, y siempre trabajando, luchando cuando las circunstancias lo requieran, sufriendo si es preciso, para ser digno de la aprobación que le habéis tributado va el viajero a continuar una vez más la ruta de la línea ya trazada. 